\title{
Why Does PSM Lead to Higher Work Stress? Exploring the Role that Organizational Identity Theory has on the Relationship between Public Service Motivation and External-Related Stress among Federal Government Employees
}

\section{Leonard Bright $^{1}$ (D)}

Accepted: 7 July 2021 / Published online: 4 August 2021

(C) The Author(s) 2021

\begin{abstract}
This study explored the effects that organizational identity and perceptions of prestige have on the relationship between public service motivation (PSM) and public employees' concerns regarding external-related work stressors. Using a sample of federal employees, the findings reveal that the relationship PSM has to perceptions of external-related stress were fully mediated by employee's organizational identity (OI) and perceptions of organizational prestige (POP). Public employees with high levels of PSM were significantly more likely to report having a stronger bond with their organization and more favorable perceptions of outsider views of their organization. The implications of these findings are discussed.
\end{abstract}

Keywords Public service motivation - Work stress · Organizational identity theory · Perceptions of organizational prestige $\cdot$ Organizational behavior

\section{Introduction}

Work stress is one of the most important topics in organizations. The World Health Organization classified stress as the Health Epidemic of the twenty-first century that comes at the cost of 300 billion dollars a year. Stress is a known cause of a variety of physical and psychological chronic diseases (Yaribeygi et al., 2017). Basically, stressed-out employees are significantly more likely to display low job satisfaction, high turnover, impaired performance, and can lead to costly health outcomes. These are many of the reasons why organizations spend millions of dollars a year on the

Leonard Bright

lbright@tamu.edu

1 Bush School of Government and Public Service, Texas A\&M University, College Station, TX, USA 
development and implementation of strategies that help employees cope with work related stress.

The consequences of stress are even more pronounced in government organizations. Government employees are on the front lines of addressing many of the most difficult and demanding problems faced by any given society, such as pandemics, terrorism, natural disasters, and a host of complex social issues. These problems expose employees to high physical dangers and deep emotional toils. These job characteristics are not likely to be highly attractive to the average citizen and thus will dampen the recruitment efforts of future employees. Also, despite the energy that public employees give to these issues, they too often receive fleeting praise and operate in environments of distrust. Negative media coverage, political bureaucratic bashing, and low citizen trust are salient external-related stressors that can influence the attitudes and behaviors of public employees.

Given the stress that is associated with public service occupations, the field requires individuals who are not only competent, but also motivated and attracted to this line of work. Many have argued that public service motivation (PSM) is a characteristic of individuals who are not only attracted to impactful work opportunities, but are also equipped to handle the environmental demands inherent in the public sector. In essence, PSM is believed to make individuals more resilient to the stress that is associated with public service work (Bakker, 2015). However, empirical research has not fully confirmed these hypotheses. In contradiction to what some have theorized, PSM has been found to be associated with enhanced stress perceptions among public employees (Giauque et al., 2013; Gould-Williams et al., 2015; Liu et al., 2015). This study seeks to understand the extent to which organizational identity theory influences this relationship.

\section{Stress and Stain}

Stress is one of the most researched areas in the general management literature. While there is no universally agreed upon definition of stress, there are several widely used concepts. For instance, Folkman and Lazarus (1984) argues that stress is a function of the relationship between the person and the environment that is appraised by the person as taxing or exceeding their resources and endangering their well-being. Similarly, Johnson and Hall (1988) and Karasek (1979) adds the importance of support and control in understanding the effects of stress on work behaviors and attitudes. They argue that work stress is a function of the relationship between the demands of the work environment and the control, resources, and support that employees have to address those demands. While stress may stem from the job demands, the effect of that stress on work outcomes is influenced by the resources and social support employees receive. Above all, scholars agree that stress alone does not automatically lead to aversive outcomes. Stress will become aversive when it leads to a strain, which is a condition that occurs when stress surpasses the available resources, coping strategies, and control available to manage it.

Along these same lines, there is also a growing understanding that stress is not inherently detrimental to the motivation and wellbeing of employees. According 
to Cavanaugh et al. (2000), there are two kinds of stress: challenge and hindrance. Challenge stresses are associated with stressful work demands that provide positive feelings and achievement. Whereas hindrance stresses are associated with work related demands that tend to constrain or interfere with an individual's work achievement. Unlike hindrance stress, challenge stress would produce positive work outcomes, because it does not hinder or interfere with the work efforts or achievement needs of employees, but instead promote personal growth and trigger positive emotions (Crawford et al., 2010). Which these distinctions in mind, this study focuses on the effects of hindrance-related stresses in government work environments.

\section{External-Related Stress in Public Workplaces}

There is a body of research that has explored stress from the standpoint of high stress government occupations such as corrections, policing, nursing, and firefighters. The findings of this research confirms that job stress is generally high in many public sector workplaces (Brown \& Campbell, 1994; Burke, 2016; Carpenter et al., 2015; Huckabee, 1992; Pendleton et al., 1989; Triplett et al., 1996; West \& West, 1989), even though there is disagreement as to whether public sector workplaces are significantly more stressful than other sectors (Hamann \& Foster, 2014; Tankha, 2006). Nonetheless, while there are many sources of stress in the public sector, one of the unique sources stems from its external environment.

Public organizations are immersed in environments of extreme scrutiny and distrust. A powerful element of this environment is the mass media. Some have described the media as an essential ingredient for democracy that provide citizens information needed to make intelligent demands on government institutions. However, the media is also known for promoting narratives and cultivating negative perceptions about government organizations that tend to lower citizen trust and confidence in them (Gerbner et al., 1980; Liu et al., 2012; Pfau et al., 1998). There is a body of research that has sought to clarify the process and effects of "mediatization" in the public sector and political institutions (Mazzoleni \& Schulz, 1999; Thorbjornsrud et al., 2014). This research revealed that the incompatibility between the goals of media and bureaucratic logic is linked to media-stress and fear among public servants (Bekkers et al., 2011; Klijn et al., 2016).

The messaging of mass media affects the opinions that citizens hold of public organizations and their support of their practices. Citizens are the ultimate beneficiaries of government action, even though national polls suggest that American citizens maintain a high level of skepticism and distrust of the federal government. According to the Pew Research Center (2020), only 20\% of Americans believe that government can be trusted to "do the right thing" always or most of the time. However, environment stressors may not impact all public organizations and employees equally. Organizations and employees who are more experienced with negative media attention and citizen criticism have developed effective coping and other organizational strategies that lessens the impact of this stress (Schillemans et al., 2019). Above all, environment stressors are associated with work-related stress (Schaufeli \& Peeters, 2000; Stevens, 2005). 


\section{Public Service Motivation}

A goal of this study is to re-explore the association that PSM has to public employees' perception of external-related stress. Public service motivation (PSM) is an altruistic need that attracts individuals to opportunities to contribute to the wellbeing of their communities and society. Scholars have found that PSM is related to a range of attitudes and behaviors in organizations, such as job satisfaction (Bright, 2008; Gould-Williams et al., 2015; Homberg et al., 2015; Kim et al., 2012; Naff \& Crum, 1999) and turnover intentions (Bright, 2007, 2008, 2013; Caillier, 2015; Christensen \& Wright, 2011; Gould-Williams et al., 2015; Liu et al., 2015; Quratulain \& Khan, 2015). However, a much smaller body of research have investigated the relationship between PSM and work stress. It has been theorized that PSM is a resource that helps public employees cope with stress and strain. According to Bakker (2015) "Those who are prepared to make sacrifices for the good of society will be better able to deal with organizational stressors because they know that dealing with those stressors serves the higher goal of helping others." Unfortunately, empirical research has not confirmed this hypothesis. Three studies have concluded that PSM is associated with higher job stress among government employees in Egypt, Switzerland, and China (Giauque et al., 2013; Gould-Williams et al., 2015; Liu et al., 2015). Based on these findings, one would expect a similar relationship to be found between PSM and the subcategory of external-related stress. While some have suggested that this relationship is due to the fact that PSM increases the performance expectations of employees (Giauque et al., 2013; Gould-Williams et al., 2015), this study seeks to understand if organizational identity is another potential explanation.

Hypothesis 1: PSM will be positively associated with external related stress. As the level of PSM increases, employees will report higher perceptions of external-related stress.

\section{Organizational Identity Theory}

Organizational identity (OI) is defined as the cognitive link or bond that exist between employees and their organizations, as well as the oneness employees experience with their organization (Ashforth \& Mael, 1989; Dutton et al., 1994). This theory is grounded in social identity and self-categorization theories that suggest that individuals are driven to classify themselves and others into social categories. These categories help individuals develop their self-concepts which answer the proverbial "Who am I?" question and define themselves relative to others (Ashforth \& Mael, 1989). Like the categories of gender, age, race, and socio-economic status, employment relationships are also an important aspect of many individuals' selfconcepts. As a result, self-concepts have work-related motivational consequences. Individuals are driven to behave in ways that are consistent with their concepts and are attracted to organizational associations that enhances their esteem. 
Additionally, the bond between organizations and employees is also influenced by outsider viewpoints (Dutton et al., 1994). On this account, perception of organizational prestige (POP) is a dimension of organizational identity theory that represents employees' understanding of how their organizations are viewed by outsiders (Dutton et al., 1994; Herrbach \& Mignonac, 2004; Mael \& Ashforth, 1992). Employees are likely to hold poorer POP perceptions, have weaker bonds to their organization, and display detrimental levels of work outcomes when they believe outsiders hold unfavorable viewpoints of their organizations (Akgunduz \& Bardakoglu, 2017; Dutton et al., 1994; Gkorezis et al., 2012; Helm, 2013; Herrbach \& Mignonac, 2004; Mishra, 2013; Tuna et al., 2016; Yim \& Schafer, 2009). It is also important to note that the salience of POP on work outcomes is not contingent on its alignment or accuracy with the actual viewpoints of outsiders. POP is salient on work outcomes purely because employees believe that their perception of outsider viewpoints are accurate.

\section{IO, POP, AND STRESS}

To what extent is IO and POP associated with stress? Stress theory suggest that the effects of stress on work outcomes is mediated by the support and resources individuals have to cope with it (Folkman \& Lazarus, 1984). Employees who have access to support mechanisms that increase their ability to cope will experience fewer negative effects of stress or threats to their wellbeing. Interestingly, one way individuals gain support to address threats to their wellbeing is through their associations with other individuals, groups, and organizations. The bond between individual, groups, and/or organizations increases not only one's self-esteem, but also one's ability to obtain protection in times of threat (Haslam et al., 2005; Newton \& Teo, 2014). For example, Haslam et al. (2005) found that the stress experienced by patients recovering from heart surgery and bomb disposal officers were strongly mediated by their perceptions of support they received from their fellow group members. The bond that develops between individuals and their organizations help protect them from aversive reactions to strain because it is the source from which group members to receive benefits and support.

Like OI, POP also contributes to the resilience individuals' have to stress. As previously mentioned, individuals are driven toward organizational associations that enhance their self-esteem. Outsider viewpoints of their organizations provide cues that individuals use to judge and value their employment associations and can also be a type of external-related stress in and of itself. Positive perceptions of outsider viewpoints are likely to not only strengthen the bond between employees and their organizations (Dutton et al., 1994), but also represent a source of encouragement for employees. Negative perceptions of outsider viewpoints are expected to work in the opposite direction. That is, employees who believe outsiders hold negative believes about their employment organization are likely to experience higher levels of stress and dissonance, which would likely weaken their bond to their organization. 
Hypothesis 2: OI will be negatively related to perceptions of external related stress. As the bond between employees and organizations strengthens, employees' perceptions of external work stress will decrease.

Hypothesis 3: POP will be positively related to OI. As employees' perceptions of outsider viewpoints of their organization grow more favorable, their bond to their organization will strengthen.

Hypothesis 4: POP will be negatively related to perceptions of external related stress. As the viewpoints that employees hold regarding outsider viewpoints of their organization become more favorable, their perceptions of external work stress will decrease.

\section{The Mediated Effects of IO, POP \& PSM}

To what extent does OI and POP influence the relationship between PSM and external related perceptions of stress? PSM is likely to be significantly related to OI and thus strengthen the psychological bond between employees and public organizations. Public organizations have meaningful opportunities to contribute the wellbeing of their community which is likely to increase the bond between employees with high levels of PSM has to these organizations (Karolidis \& Vouzas, 2019; Miao et al., 2019). Similarly, one would expect PSM to be significantly associated with POP. According to the perceived public service efficacy (PPSE) theory, employees tend assume that citizens share their viewpoints regarding the benefits of government programs (Boardman \& Sundquist, 2009). In line with this reasoning, employees with high levels of PSM are likely to believe that public organizations offer valuable contributions to society (because of their own attraction to these opportunities) and thus are likely to believe that the members of the public who receive these benefits also share their positive viewpoints? As a result, while PSM may maintain a direct associate to work stress, it will also maintain an indirect relationship through its association with OI and POP.

Hypothesis 5: PSM will be positively associated with OI. As the levels of PSM increase in employees, their bond to public organizations will strengthen.

Hypothesis 6: PSM will be positively associated with POP. As the level of PSM increase in employees, their perceptions of outsider viewpoints of their organization will grow more favorable.

Hypothesis 7: OI and POP will partially mediate the association that PSM has to external related stress perceptions.

\section{Methodology}

The data for this study was drawn in 2017 from federal employees working for the Transportation Security Administration (TSA) within the Department of Homeland Security in the State of Oregon. The survey population was employed at the same occupational classification level and served on the front-line of the agency. As front-line 
employees, their work required daily direct contact with citizens. To stay up to date on the latest rules and regulations that governed their work, all employees had to undergo monthly recertification training sessions. Agency officials integrated the survey instrument into one of these required training sessions. The employees were provided with a workspace and instructions on how to complete the survey. The survey instructed the employees that their participation in the study was completely voluntary; their individual answers would be kept confidential; they could refuse to answer any question that made them uncomfortable; and that they could end the survey at any time with no penalty or loss. Five-hundred and fifty-seven $(\mathrm{N}=557)$ useable surveys were collected with a response rate of $97 \%$. The study sample was representative of the study population in terms of age, gender, and full-time status.

Several major variables were collected in this study: OI, POP, PSM, externalrelated stressors. See Table 1 for a description of the variables and coding strategies. IO and POP was collected several questions taken from a modified version of the Mael and Ashforth (1992) multi-item scale. For instance IO, the respondents were asked whether they agreed or disagreed that "When I talk about this organization, I usually say 'we' rather than 'they', and whether 'This organization's successes are my successes". These questions maintained a satisfactory fit to the data (Cronbach's $\alpha=0.777$ ). POP was collected by asking the respondents whether "It is prestigious to be an employee of the TSA" and if the "TSA is one of the best government agencies in America". These questions showed a proficient level of reliability (Cronbach's $\alpha=0.815$ ). PSM was collected using the (Kim, 2009) 12-item revision of Perry (1996) 24-item PSM scale and had good internal reliability (Cronbach's $\alpha=0.843)$.

External-related work stress was collected using two question: How concerned are you with the viewpoints that citizens hold about TSA? How concerned are you with negative media coverage of TSA? The responds to these questions demonstrated a good fit to the data (Cronbach's $\alpha=0.872$ ) and were summed. In addition, several demographic variables (i.e., age, education, gender, minority status, and work experience) were collected and used as potential control variables.

The analysis of this study was conducted in three stages. First, a bivariate correlation analysis was conducted to confirm the relationships among the study variables. Any control variables that were not correlated with work stress were removed from subsequent analysis to enhance the power of the study and parsimony. Second, as structural equation modeling in AMOS was used to explore the relationships among the study variables. Third, bootstrap analysis will be used to test the significances of any mediation effects found. Statistical significance was set at 0.05 , two-tailed. All regression weights are standardized maximum likelihood estimates, unless otherwise noted (Fig. 1).

\section{Findings}

Table 2 displays the demographic characteristics of the sample. Most of the respondents were between 18-40 years old (52\%), had some to no college experience (53\%), were male $(55 \%)$, identified as White $(75 \%)$, and gained an average of seven years 


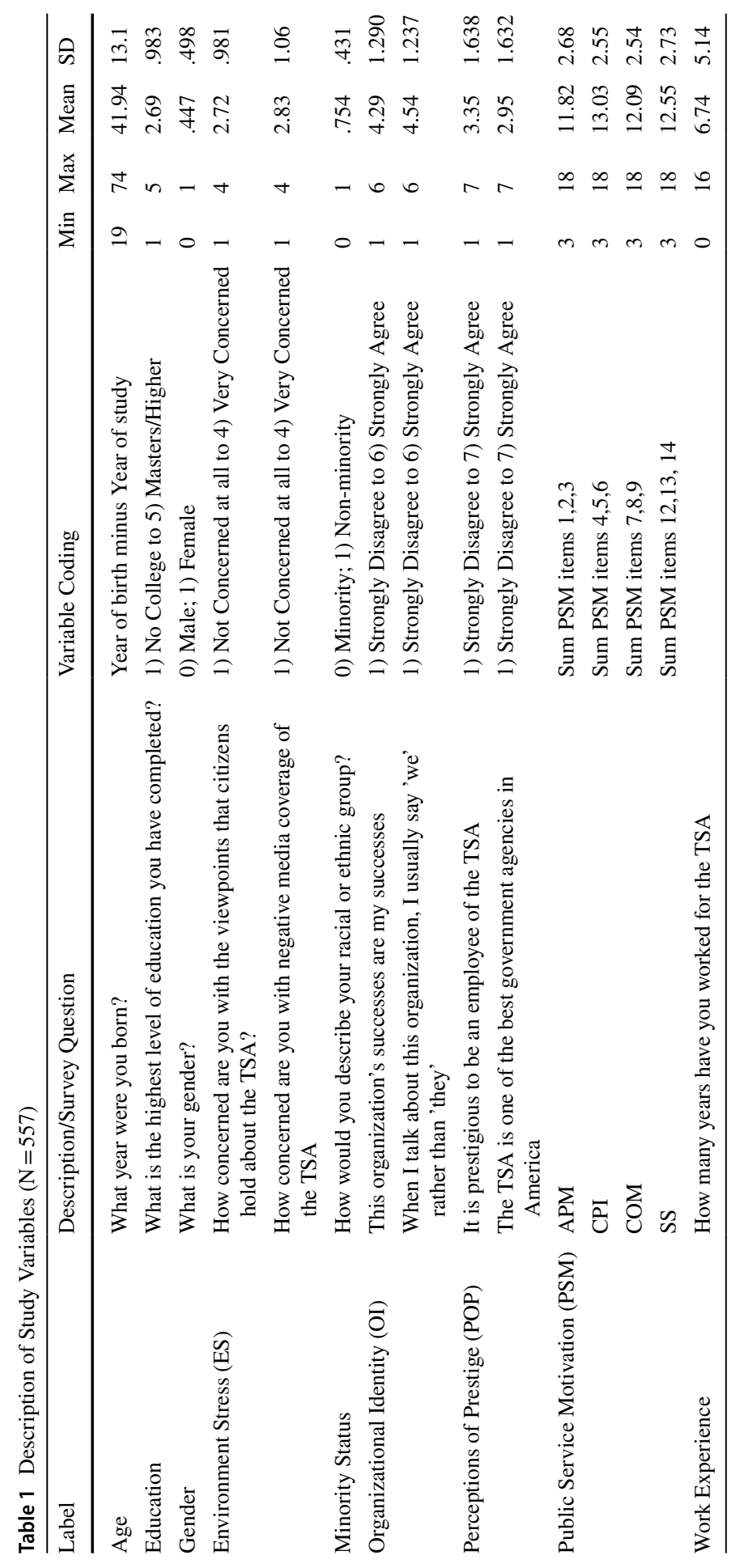




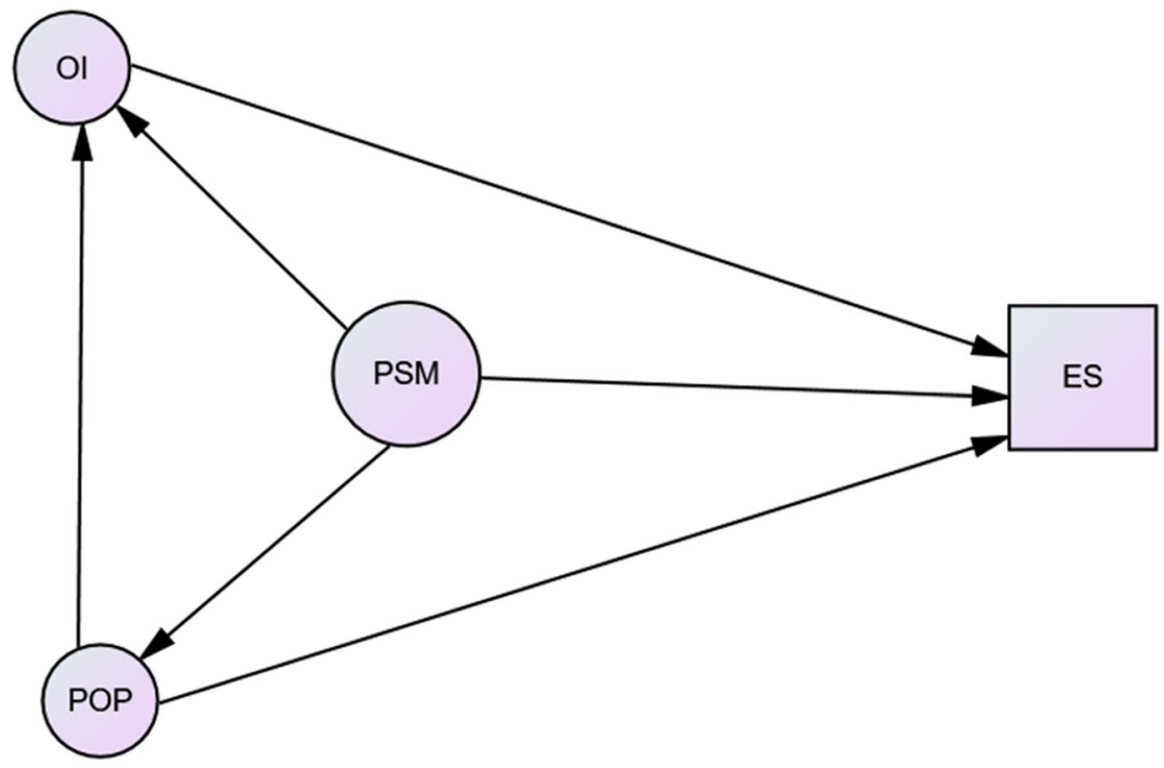

Fig. 1 Study model

of work experience in the TSA. As shown in Table 3, the respondents' perceptions of environmental stress were high and consistent. When asked how concerned they were with the viewpoints that citizens hold or with negative media coverage, over sixty percent were somewhat to very concerned about these external factors. However, the means of the responses regarding citizen viewpoints $(\bar{X}=2.7)$ and media coverage $(\bar{X}=2.8)$ indicates that the respondents were slightly more concerns about negative media coverage than negative citizen viewpoints.

Table 4 presents the correlations among the study variables. There are several notable relationships, especially regarding age, experience, and gender. For example, perceptions of external-related stress correlated strongly with the age, experience, and gender of the respondents. The respondents who were older in terms of their age and identified as female were significantly more likely to report experiencing high levels of external stress when compared to their younger and male identified counterparts. Similarly, the finding regarding years of work experience contradicts existing research that suggest that more experienced employees have more effective stress coping strategies that lessens the impact of this external-related stress (Schillemans et al., 2019). In this study, the respondents with greater years of work experience reported significantly greater concerns about the external-related stressors when compared to their younger counterparts.

The finding also demonstrate that IO was strongly correlated with the age and gender of the respondents. The respondents who were older or identified as female reporting having significantly stronger bonds to their organization than their male and younger counterparts. It is also noteworthy that years of experience of the respondents was the only demographic characteristic that was associated with 
Table 2 Respondents Characteristics and Control Variables

\begin{tabular}{|c|c|c|}
\hline & $\mathrm{N}$ & $\%$ \\
\hline \multicolumn{3}{|l|}{ Age } \\
\hline 18 to 30 years old & 131 & $25 \%$ \\
\hline 31 to 40 years old & 143 & $27 \%$ \\
\hline 41 to 50 years old & 90 & $17 \%$ \\
\hline $51+$ years old & 167 & $31 \%$ \\
\hline \multicolumn{3}{|l|}{ Education Level } \\
\hline No College & 35 & $6 \%$ \\
\hline Some College & 260 & $47 \%$ \\
\hline AA/Technical & 122 & $22 \%$ \\
\hline BA & 123 & $22 \%$ \\
\hline Masters/Higher & 17 & $3 \%$ \\
\hline \multicolumn{3}{|l|}{ Gender } \\
\hline Male & 293 & $55 \%$ \\
\hline Female & 237 & $45 \%$ \\
\hline \multicolumn{3}{|l|}{ Race and Ethnicity } \\
\hline Black/African American & 18 & $3 \%$ \\
\hline Hispanic/ Latino & 22 & $4 \%$ \\
\hline White/Caucasian & 399 & $75 \%$ \\
\hline Asian/Pacific Islander & 40 & $8 \%$ \\
\hline Native American/ Alaska Native & 5 & $1 \%$ \\
\hline Multi-Racial & 47 & $9 \%$ \\
\hline \multicolumn{3}{|l|}{ Work Experience } \\
\hline 1 year and less & 130 & $23 \%$ \\
\hline 1 to 5 years & 143 & $26 \%$ \\
\hline 5 to 10 years & 130 & $23 \%$ \\
\hline 10 years and more & 154 & $28 \%$ \\
\hline
\end{tabular}

their perceptions of outsider viewpoints. As the years of experience increased, the respondents held increasingly negative POP perceptions.

Given the significant bivariate relationships found between age, years of experience and several of the study variables, two SEM models were analyzed. The first model investigated the relationships among the study variables and the control variables of age, years of experience, and gender. The second model investigated these relationships without the control variables. The second model did not result in any meaningful differences. As a result, the first model was adopted for the sake of parsimony and improved model fit. The fit indices indicate that the statistical model has a good fit to the data $(\mathrm{GFI}=0.959, \mathrm{NFI}=0.944, \mathrm{CFI}=0.955, \mathrm{RMSEA}=0.082)$. The SEM findings are displayed in Table 5 and Fig. 2.

Subsequently, the seven hypotheses that were advanced in this study received mixed support. Hypotheses 3, 4, 5, and 6 were supported by the data. OI and POP was found to be positively associated. The respondent who reported having more favorable perceptions of outsider viewpoints of their organization also had 


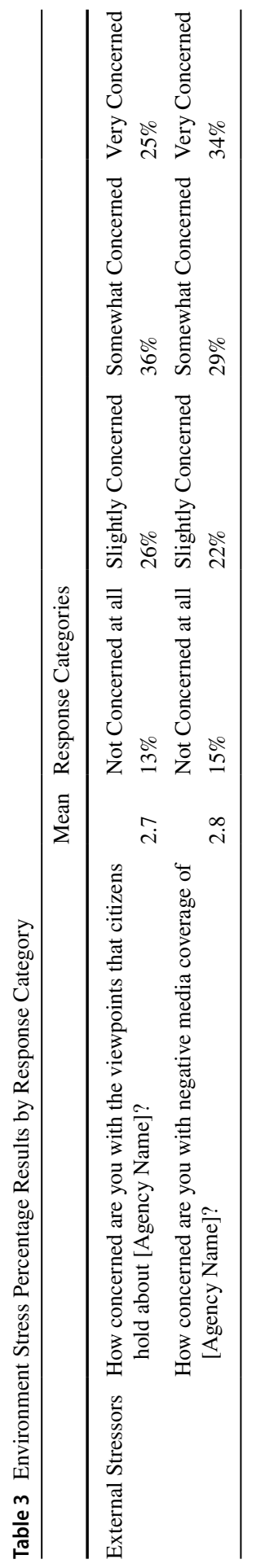


Table 4 Bivariate Correlations Among Study Variables

\begin{tabular}{|c|c|c|c|c|c|c|c|c|c|}
\hline & 1 & 2 & 3 & 4 & 5 & 6 & 7 & 8 & 9 \\
\hline 1. Age & 1 & & & & & & & & \\
\hline 2. Education & .022 & 1 & & & & & & & \\
\hline 3. Experience & $.501^{* *}$ & $-.129^{* *}$ & 1 & & & & & & \\
\hline 4. Gender & $-.089^{*}$ & -.065 & $-.092^{*}$ & 1 & & & & & \\
\hline 5. Minority & $.233^{* *}$ & -.023 & $.098^{*}$ & -.017 & 1 & & & & \\
\hline 6. OI & $.159^{* *}$ & -.072 & -.016 & $.093^{*}$ & .078 & 1 & & & \\
\hline 7. POP & .065 & -.055 & $-.144^{* *}$ & .035 & -.009 & $.392^{* *}$ & 1 & & \\
\hline 8. PSM & -.013 & .055 & $-.121^{* *}$ & -.049 & -.009 & $.467^{* *}$ & $.252^{* *}$ & 1 & \\
\hline 9. ES & $.164^{* *}$ & .012 & $.113^{* *}$ & $.091^{*}$ & .072 & $.507^{* *}$ & -.014 & $.224^{* *}$ & 1 \\
\hline
\end{tabular}

significantly stronger bonds to their organization than their counterparts with less favorable perceptions of outsider viewpoints. POP was also found to be negatively related to external related stress. The respondents reported significantly lower external related stress when their viewpoints about outsider viewpoints of their organization were favorable. Additionally, PSM was significantly and positively related to both OI and POP. The respondents with high levels of PSM reported having significantly stronger bonds to their organization and more favorable POP perceptions.

However, the findings of this study did not support Hypotheses 1, 2 and 7. In contradiction to the stated hypothesis, OI was found to be positively related to external-related work stress. The respondents who reporting having strong bonds to their organization, also reported experiencing significantly higher levels of externalrelated stress than their counterparts with weaker identity bonds. Similarly, PSM was found to have no meaningful relationship to external related stress in this study. The respondents stress perceptions were not directly due to their varying levels of PSM, especially when the influence of OI and POP were considered. This is preliminary evidence that OI and POP completely mediated the relationship between PSM and external related stress. However, to confirm these findings, Bootstrapping was to test the effects of OI and POP in this study. A full mediation is present when the significance of the indirect pathway reduces the significance of the direct pathway, while a partial mediation is present when both the direct and indirect pathways are significant, even though one pathway may be dominant.

Table 5 Study Variables Estimates by Model Paths

\begin{tabular}{|c|c|c|}
\hline Model Paths & $\beta$ & $\mathrm{P}$ \\
\hline $\mathrm{POP}<--\mathrm{PSM}$ & .229 & $* * *$ \\
\hline $\mathrm{OI}<--\mathrm{PSM}$ & .219 & $* * *$ \\
\hline $\mathrm{OI}<--\mathrm{POP}$ & .266 & $* * *$ \\
\hline $\mathrm{ES}<--\mathrm{PSM}$ & .064 & .307 \\
\hline $\mathrm{ES}<--\mathrm{OI}$ & .838 & $* * *$ \\
\hline $\mathrm{ES}<--\mathrm{POP}$ & -.351 & $* * *$ \\
\hline
\end{tabular}




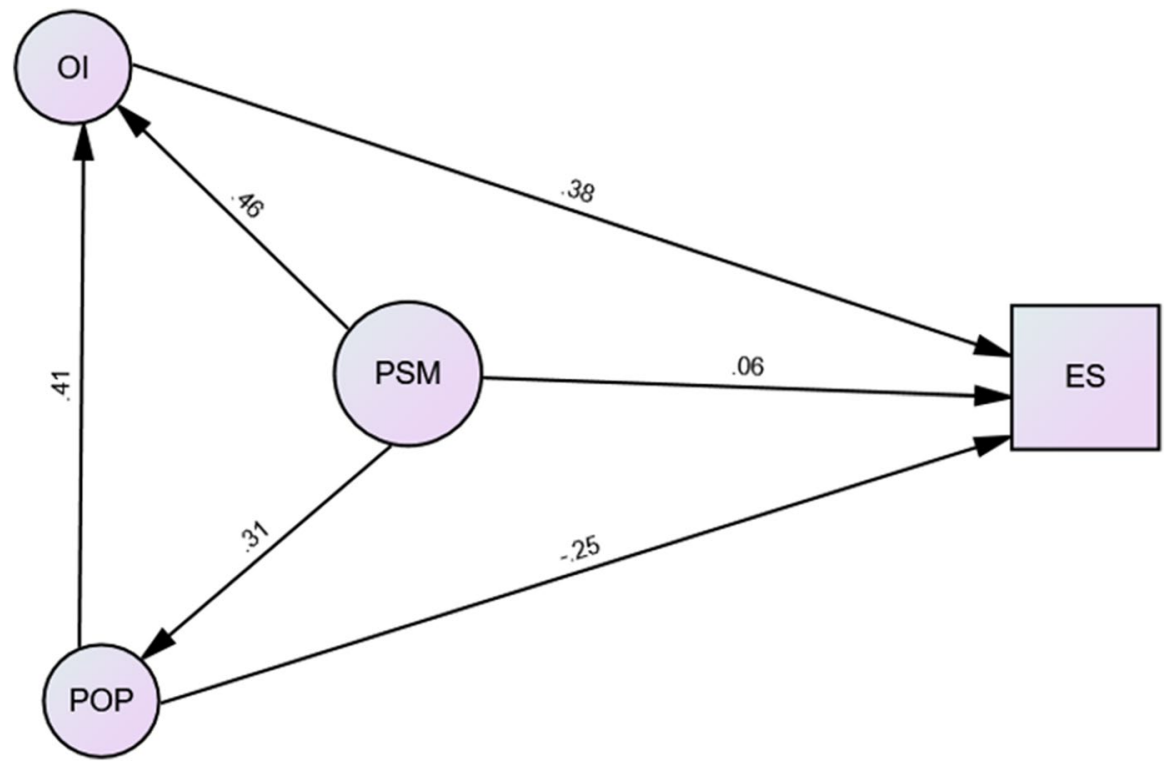

Fig. 2 Study results

As shown in Table 6, the influence of PSM on external stress was fully mediated by OI and POP. These findings confirms that while PSM had no direct relationship to external stress, it kept an indirect and meaningful relationship to external stressors though its associations with OI and POP. However, the strongest path through which PSM influences external-related stress was though its relationship to OI. That is, as the respondents' level of PSM increased, they reported having higher identity to their organization, which was found to be positively associated with increasing levels of concern about negative citizen and media attention.

\section{Conclusion}

The goal of this study was to explore the extent to which OI and POP mediated the relationship between PSM and external related stress. Specifically, this study sought to better understand whether organizational identity theory explained the finding in

Table 6 Bootstrap Mediation Analysis Unstandardized Results

\begin{tabular}{llll}
\hline Analysis & $\begin{array}{l}\text { Direct Effect } \\
(\mathrm{x} \rightarrow \mathrm{y})\end{array}$ & Indirect Effect & Result \\
\hline $\mathrm{PSM} \rightarrow \mathrm{POP} \rightarrow \mathrm{ES}$ & .209 & $-.080^{* *}$ & Full \\
$\mathrm{PSM} \rightarrow \mathrm{OI} \rightarrow \mathrm{ES}$ & .209 & $.183^{* *}$ & Full \\
$\mathrm{PSM} \rightarrow \mathrm{POP} \rightarrow \mathrm{OI} \rightarrow \mathrm{ES}$ & .209 & $.051^{* *}$ & Full \\
${ }^{* *}=\mathrm{p} \leq .001$ & & &
\end{tabular}


the existing research that PSM directly leads to higher stress among public employees. The findings of this study reveal a complex set of relationships. Surprisingly, PSM had no direct relationship with external related stress in this study. Instead, PSM maintained an indirect relationship to stress through its relationships with OI and POP. As the level of PSM increased, the respondents were significantly more likely to display stronger bonds to their organization and more favorable perceptions of outsider viewpoints. However, the relationships that OI and POP had to work related stress were conflicting. OI was positively associated with work stress, while POP was negatively related. There are several important implications of these findings.

For one, this study provides greater clarity about the association that PSM has to work stress. Existing research suggested that PSM was positively related to work stress, because it raised the performance expectations of employees (Giauque et al., 2013; Gould-Williams et al., 2015; Liu et al., 2015). However, the findings of this study offers an alternative explanation. PSM was not directly associated to work stress (as measured in terms of concerns about negative media coverage or citizen opinions) when the strength of their bond to their organization and their perceptions of external viewpoints were considered. This suggest that the direct association that past research found between PSM and work stress may be due to the omission of these important mediating variables. From the perspective of this study, PSM may also increase work related stress because the stressors are challenges to their organizational membership. PSM appears to enhance OI, which then makes employees more sensitive to external opinions about their organization.

Secondly, while the findings of this study demonstrate that OI, POP, and PSM are positively related, the moderate correlational strength of these relationships indicate that they are not necessarily guaranteed to co-exist equally. For example, it is possible for a public employee to have favorable POP in ways that does not lead to a stronger bond to their organization. Under these circumstances, employees with high levels of PSM are likely to report having favorable perceptions of outsider viewpoints and lower stress perceptions. However, when PSM and POP strengthen the bond between employees and public organizations, the benefits that POP has to stress are likely to be overridden. In this case, employees with high levels of PSM are likely to report significantly higher external-related stress, over and above the favorable effects of POP.

Lastly, the findings of this study offers a mixed bag of advice for public managers and supervisors. On one hand, it supports efforts to foster PSM and POP in organizations given their relationship to a range of work outcomes, such absenteeism, commitment, job satisfaction, turnover intentions, and extra-role behaviors (Bright, 2021a, b, c; Rho et al., 2015). This study adds to this body of research by demonstrating that PSM and POP also works to lower stress among public employees. However, the relationships that OI had to PSM and POP, offers a measure of caution. While there are benefits of fostering tightly knitted organizations, it is important the managers also provide these employees with strategies they can use to cope with their external concerns. The stress that employees with high levels of PSM experience because of their attachment to public organizations is a potential sign that strain is imminent if adequate support is not provided that helps these employees cope. 
Moreover, in addition to the contributions of this study, there are weaknesses that may have influenced the interpretation of the findings. One weakness of this study is that it drew its data from Oregon's Transportation Security Agency that may limit the generalizability the findings. Future research should confirm the findings using a broader sample of organizations. A second weakness of this study is its cross-sectional design. Cross-sectional designs limits interpretations of causality. For example, this study assumed that OI and POP were consequences of PSM. However, it could be the case that fostering strong bonds between organizations and employees is a condition that increases the likelihood that employees act in altruistic ways in their jobs. Longitudinal or experimental research designs are better equipped to isolate and test causal relationships.

Nonetheless, with the weaknesses in mind, this study provides greater clarity about the relationships among PSM, OI, POP, and work-related stress. While PSM can lead to lower external related stress by improving POP, PSM relationship to OI can undue these benefits. These findings point to the importance of fostering high levels of PSM in public organizations, while also providing resources that help these committed employees cope with hostile external environments.

\section{Declarations}

Informed Consent Yes.

Ethical Approval Granted from Institution.

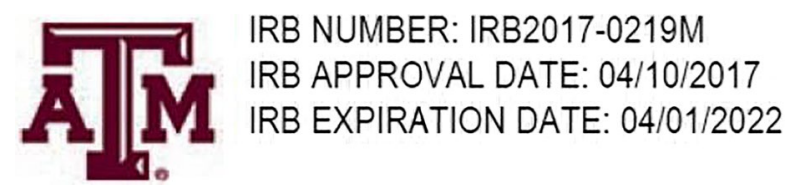

\section{Conflict of Interest None.}

Open Access This article is licensed under a Creative Commons Attribution 4.0 International License, which permits use, sharing, adaptation, distribution and reproduction in any medium or format, as long as you give appropriate credit to the original author(s) and the source, provide a link to the Creative Commons licence, and indicate if changes were made. The images or other third party material in this article are included in the article's Creative Commons licence, unless indicated otherwise in a credit line to the material. If material is not included in the article's Creative Commons licence and your intended use is not permitted by statutory regulation or exceeds the permitted use, you will need to obtain permission directly from the copyright holder. To view a copy of this licence, visit http://creativecommons.org/licen ses/by/4.0/. 


\section{References}

Akgunduz, Y., \& Bardakoglu, O. (2017). The impacts of perceived organizational prestige and organization identification on turnover intention: The mediating effect of psychological empowerment. Current Issues in Tourism, 20(14), 1510-1526.

Ashforth, B. E., \& Mael, F. (1989). Social identity theory and the organization. Academy of Management Review, 14(1), 20-39.

Bakker, A. B. (2015). A job demands-resources approach to public service motivation. Public Administration Review, 75(5), 723-732.

Bekkers, V., Moody, R., \& Edwards, A. (2011). Micro-mobilization, social media and coping strategies: Some dutch experiences. Policy \& Internet, 3(4), 1-29.

Boardman, C., \& Sundquist, E. (2009). Toward understanding work motivation worker attitudes and the perception of effective public service. The American Review of Public Administration, 39(5), 519-535.

Bright, L. (2007). Does person-organization fit mediate the relationship between public service motivation and the job performance of public employees? Review of Public Personnel Administration, 27(4), 361-379.

Bright, L. (2008). Does public service motivation really make a difference on the job satisfaction and turnover intentions of public employees? The American Review of Public Administration, 38(2), $149-166$.

Bright, L. (2013). Where does public service motivation count the most in government work environments? A preliminary empirical investigation and hypotheses. Public Personnel Management, 42(1), 5-26.

Bright, L. (2021a). Does perceptions of organizational prestige mediate the relationship between public service motivation, job satisfaction, and the turnover intentions of federal employees? Public Personnel Management, 50(3), 408-429.

Bright, L. (2021b). An exploratory study of the consequences of perceived organizational prestige on a range of work attitudes and behaviors among public employees: A call to future research. Public Administration Research, 10(1), 26-40.

Bright, L. (2021c). Does person organization fit and person-job fit mediate the relationship between public service motivation and work stress among U.S. federal employees? Administrative Sciences, 11(2), 1-37.

Brown, J. M., \& Campbell, E. A. (1994). Stress and policing: Sources and strategies. Wiley.

Burke, R. J. (2016). Stress in policing: Sources, consequences and interventions. Routledge.

Caillier, J. G. (2015). Towards a better understanding of public service motivation and mission valence in public agencies. Public Management Review, 17(9), 1217-1236.

Carpenter, G. S. J., Carpenter, T. P., Kimbrel, N. A., Flynn, E. J., Pennington, M. L., Cammarata, C., Zimering, R. T., Kamholz, B. W., \& Gulliver, S. B. (2015). Social support, stress, and suicidal ideation in professional firefighters. American Journal of Health Behavior, 39(2), 191-196.

Cavanaugh, M. A., Boswell, W. R., Roehling, M. V., \& Boudreau, J. W. (2000). An empirical examination of self-reported work stress among US managers. Journal of Applied Psychology, 85(1), 65.

Christensen, R. K., \& Wright, B. E. (2011). The effects of public service motivation on job choice decisions: Disentangling the contributions of person-organization fit and person-job fit. Journal of Public Administration Research and Theory, 21(4), 723-743.

Crawford, E. R., LePine, J. A., \& Rich, B. L. (2010). Linking job demands and resources to employee engagement and burnout: A theoretical extension and meta-analytic test. Journal of Applied Psychology, 95(5), 834.

Dutton, J. E., Dukerich, J. M., \& Harquail, C. V. (1994). Organizational images and member identification. Administrative Science Quarterly, 39, 239-263.

Folkman, S., \& Lazarus, R. S. (1984). Stress, appraisal, and coping. New York: Springer Publishing Company.

Gerbner, G., Gross, L., Morgan, M., \& Signorielli, N. (1980). The "mainstreaming" of America: Violence profile number 11. Journal of Communication, 30(3), 10-29.

Giauque, D., Anderfuhren-Biget, S., \& Varone, F. (2013). Stress perception in public organisations: Expanding the job demands-job resources model by including public service motivation. Review of Public Personnel Administration, 33(1), 58-83. 
Gkorezis, P., Mylonas, N., \& Petridou, E. (2012). The effect of perceived external prestige on Greek public employees' organizational identification: Gender as a moderator. Gender in Management, 27(1), $51-62$

Gould-Williams, J. S., Mostafa, A. M. S., \& Bottomley, P. (2015). Public service motivation and employee outcomes in the Egyptian public sector: Testing the mediating effect of person-organization fit. Journal of Public Administration Research and Theory, 25(2), 597-622.

Hamann, D. J., \& Foster, N. T. (2014). An exploration of job demands, job control, stress, and attitudes in public, nonprofit, and for-profit employees. Review of Public Personnel Administration, 34(4), 332-355.

Haslam, S. A., O’Brien, A., Jetten, J., Vormedal, K., \& Penna, S. (2005). Taking the strain: Social identity, social support, and the experience of stress. British Journal of Social Psychology, 44(3), $355-370$.

Helm, S. (2013). A matter of reputation and pride: Associations between perceived external reputation, pride in membership, job satisfaction and turnover intentions. British Journal of Management, 24(4), 542-556.

Herrbach, O., \& Mignonac, K. (2004). How organisational image affects employee attitudes. Human Resource Management Journal, 14(4), 76-88.

Homberg, F., McCarthy, D., \& Tabvuma, V. (2015). A meta-analysis of the relationship between public service motivation and job satisfaction. Public Administration Review, 75(5), 711-722.

Huckabee, R. G. (1992). Stress in corrections: An overview of the issues. Journal of Criminal Justice, 20(5), 479-486.

Johnson, J. V., \& Hall, E. M. (1988). Job strain, work place social support, and cardiovascular disease: A cross-sectional study of a random sample of the Swedish working population. American Journal of Public Health, 78(10), 1336-1342.

Karasek, R. A. (1979). Job demands, job decision latitude, and mental strain: Implications for job redesign. Administrative Science Quarterly, 24, 285-308.

Karolidis, D., \& Vouzas, F. (2019). From PSM to helping behavior in the contemporary Greek public sector: The roles of organizational identification and job satisfaction. Public Performance \& Management Review, 42(6), 1418-1447.

Kim, S. (2009). Revising Perry's measurement scale of public service motivation. American Review of Public Administration, 39(2), 149-163.

Kim, S., Vandenabeele, W., Wright, B. E., Andersen, L. B., Cerase, F. P., Christensen, R. K., Desmarais, C., Koumenta, M., Leisink, P., Liu, B., Palidauskaite, J., Pedersen, L. H., Perry, J. L., Ritz, A., Taylor, J., \& Vivo, P. D. (2013). Investigating the structure and meaning of public service motivation across populations: developing an international instrument and addressing issues of measurement invariance. Journal of Public Administration Research and Theory, 23(1), 79-102.

Klijn, E. H., van Twist, M., van der Steen, M., \& Jeffares, S. (2016). Public managers, media influence, and governance: Three research traditions empirically explored. Administration \& Society, 48(9), 1036-1058.

Liu, B., Yang, K., \& Yu, W. (2015). Work-related stressors and health-related outcomes in public service: Examining the role of public service motivation. The American Review of Public Administration, 45(6), 653-673.

Liu, B. F., Horsley, J. S., \& Yang, K. (2012). Overcoming negative media coverage: Does government communication matter? Journal of Public Administration Research and Theory, 22(3), 597-621.

Mael, F., \& Ashforth, B. E. (1992). Alumni and their alma mater: A partial test of the reformulated model of organizational identification. Journal of Organizational Behavior, 13(2), 103-123.

Mazzoleni, G., \& Schulz, W. (1999). "Mediatization" of politics: A challenge for democracy? Political Communication, 16(3), 247-261.

Miao, Q., Eva, N., Newman, A., \& Schwarz, G. (2019). Public service motivation and performance: The role of organizational identification. Public Money \& Management, 39(2), 77-85.

Mishra, S. K. (2013). Perceived external prestige and employee outcomes: Mediation effect of organizational identification. Corporate Reputation Review, 16(3), 220-233.

Naff, K. C., \& Crum, J. (1999). Working for America does public service motivation make a difference? Review of Public Personnel Administration, 19(4), 5-16.

Newton, C., \& Teo, S. (2014). Identification and occupational stress: A stress-buffering perspective. Human Resource Management, 53(1), 89-113.

Pendleton, M., Stotland, E., Spiers, P., \& Kirsch, E. (1989). Stress and strain among police, firefighters, and government workers: A comparative analysis. Criminal Justice and Behavior, 16(2), 196-210. 
Perry, J. (1996). Measuring public service motivation: An assessment of construct reliability and validity. Journal of Public Administration Research and Theory, 6(1), 5-22.

Pew Research Center. (2020). Americans' views of government: Low trust, but some positive performance ratings. Retrieved from www.pewresearch.org

Pfau, M., Moy, P., Radler, B., \& Bridgeman, M. K. (1998). The influence of individual communication media on public confidence in democratic institutions. Southern Communication Journal, 63(2), 91-112.

Quratulain, S., \& Khan, A. K. (2015). Red tape, resigned satisfaction, public service motivation, and negative employee attitudes and behaviors: Testing a model of moderated mediation. Review of Public Personnel Administration, 35(4), 307-332.

Rho, E., Yun, T., \& Lee, K. (2015). Does organizational image matter? Image, identification, and employee behaviors in public and nonprofit organizations. Public Administration Review, 75(3), $421-431$.

Schaufeli, W. B., \& Peeters, M. C. (2000). Job stress and burnout among correctional officers: A literature review. International Journal of Stress Management, 7(1), 19-48.

Schillemans, T., Karlsen, R., \& Kolltveit, K. (2019). Why do civil servants experience media-stress differently and what can be done about it? Policy \& Politics, 47(4), 599-620.

Stevens, D. J. (2005). Police officer stress and occupational stressors: Before and after 9/11. In Copes (Ed.), Policing and stress (pp. 1-24). Pearson Education Inc.

Tankha, G. (2006). A comparative study of role stress in government and private hospital nurses. Journal of Health Management, 8(1), 11-22.

Thorbjornsrud, K., Figenschou, T. U., \& Ihlen, Ø. (2014). Mediatization in public bureaucracies: A typology. Communications: The European Journal of Communication Research, 39(1), 3-22.

Triplett, R., Mullings, J. L., \& Scarborough, K. E. (1996). Work-related stress and coping among correctional officers: Implications from organizational literature. Journal of Criminal Justice, 24(4), 291-308.

Tuna, M., Ghazzawi, I., Yesiltas, M., Tuna, A. A., \& Arslan, S. (2016). The effects of the perceived external prestige of the organization on employee deviant workplace behavior: The mediating role of job satisfaction. International Journal of Contemporary Hospitality Management, 28(2), 366-396.

West, J. P., \& West, C. M. (1989). Job stress and public sector occupations: Implications for personnel managers. Review of Public Personnel Administration, 9(3), 46-65.

Yaribeygi, H., Panahi, Y., Sahraei, H., Johnston, T. P., \& Sahebkar, A. (2017). The impact of stress on body function: A review. EXCLI Journal, 16, 1057-1072.

Yim, Y., \& Schafer, B. D. (2009). Police and their perceived image: How community influence officers' job satisfaction. Police Practice and Research: An International Journal, 10(1), 17-29.

Publisher's Note Springer Nature remains neutral with regard to jurisdictional claims in published maps and institutional affiliations. 